\title{
Single-atom $\mathrm{Mn}-\mathrm{N}_{4}$ Sites Catalyzed Peroxone Reaction for
}

\section{Efficient Production of Hydroxyl Radicals under Acidic}

\section{Solution}

Zhuang $\mathrm{Guo}^{1,2}+$, Yongbing Xie ${ }^{1}$, Jiadong Xiao3, Zhi-Jian Zhao4, Yuxian Wang5, Zhaomeng $\mathrm{Xu}^{1,2}$, Yi Zhang ${ }^{1}$, Lichang Yin ${ }^{6 *}$, Hongbin $\mathrm{Cao}^{1 *}$, \& Jinlong Gong4*

'Beijing Engineering Research Center of Process Pollution Control, National Engineering Laboratory for Hydrometallurgical Cleaner Production Technology, Institute of Process Engineering, Chinese Academy of Science, Beijing 10019o, China.

${ }^{2}$ University of Chinese Academy of Sciences, Beijing 100049, China.

IInorganic Chemistry and Catalysis, Debye Institute for Nanomaterials Science, Utrecht University, David de Wiedgebouw, Universiteitsweg 99, 3584 CG Utrecht, The Netherlands

${ }^{4}$ School of Chemical Engineering \& Technology, Tianjin University, Collaborative Innovation Center of Chemical Science and Engineering (Tianjin), Tianjin 300072, China

${ }^{5}$ State Key Laboratory of Heavy Oil Processing, China University of Petroleum (Beijing), 18 Fuxue Road, Beijing 102249, China.

${ }^{6}$ Shenyang National Laboratory for Materials Science, Institute of Metal Research, Chinese Academy of Sciences, 72 Wenhua Road, Shenyang 110016, China 


\section{Methods}

\section{Materials synthesis.}

In a facile and typical procedure, dicyandiamide $(1 \mathrm{~g})$ is dissolved in deionized water $(20 \mathrm{~mL})$ at $60{ }^{\circ} \mathrm{C}$, and then appropriate amount of $\mathrm{MnCl}_{2} \cdot 4 \mathrm{H}_{2} \mathrm{O}$ is added into the solution and stirred sufficiently. The solution is heated to $110{ }^{\circ} \mathrm{C}$ to completely remove water, then the obtained mixture is heated from room temperature to $600{ }^{\circ} \mathrm{C}$ at a rate of $10{ }^{\circ} \mathrm{C} / \mathrm{min}$ and maintained at the temperature for $3 \mathrm{~h}$ under nitrogen atmosphere. The sample is notated as Mn-CN. Similarly, catalysts with different Mn mass loading are prepared with the same method. In addition, $\mathrm{g}-\mathrm{C}_{3} \mathrm{~N}_{4}$ and $\mathrm{MnCl}_{2}$ are also synthetized using individual precursor, respectively.

\section{Characterization.}

The crystal structures of the catalysts are characterized by X-ray diffraction (XRD) with a $\mathrm{Cu} \mathrm{K} \alpha$ irradiation, and their micro structure are analyzed by transmission electron microscopy (TEM, JEOL, JEM-210of). The high-angle annular dark-field scanning transmission electron microscopy (HAADFSTEM) images and STEM-mapping are performed by using a Titan Cubed Themis 6o-30o. X-ray photoelectron spectroscopy (XPS) measurement is performed on an ESCALAB 250Xi instrument. The Mn concentrations of the catalysts are detected on the inductively coupled plasma optical emission spectrometer (ICP-OES, 6300). Raman spectra measurement is performed on a JY HR-8oo instrument. The excitation wavelength is $785 \mathrm{~nm}$. The catalyst $(50 \mathrm{mg})$ is mixed with $\mathrm{H}_{2} \mathrm{O}_{2}(10 \mu \mathrm{L})$ in aqueous solution (1 mL, pH 3). X-ray adsorption spectroscopy (XAS) of Mn K-edge are collected at $1 W_{13}$ station in Beijing Synchrotron Radiation Facility (BSRF). The XAS raw data are background-subtracted, normalized, and Fourier transformed by standard procedures with the ATHENA in IFEFFIT software. The least-squares curve fitting is performed using ARTEMIS module to obtain the quantitative structural parameters.

\section{DFT calculation.}

Density functional theory calculations are performed using the projector augmented wave method and a plane-wave basis set as implemented in the Vienna ab-initio simulation package. The PerdewBurke-Ernzerhof functional for the exchange-correlation term is used for all calculations ${ }^{1-4}$. The energy cutoff for the plane wave basis set is set to be $400 \mathrm{eV}$. For $\mathrm{H}$ the $1 \mathrm{~s}$ state, for $\mathrm{C}, \mathrm{N}$, and $\mathrm{O}$ the $2 \mathrm{~s}$ and $2 \mathrm{p}$ states, for $\mathrm{Mn}$ the $3 \mathrm{p}$ and $3 \mathrm{~d}$ states are treated as valence states. The lattice constant of monolayer $\mathrm{g}-\mathrm{C}_{3} \mathrm{~N}_{4}$ is calculated to be $\mathrm{a}=16.9 \AA$ and $\mathrm{b}=12.7 \AA$, which is slightly larger than the experimental values $(a=16.7 \AA$ and $b=12.4 \AA$ ) 5. Spin-polarization is included in all computations and dipole corrections is involved in the calculations for charged systems. The vacuum thickness is set to be $15 \AA$ A along the $\mathrm{z}$ direction. A Monkhorst-Pack $(3 \times 4 \times 1)$ k-point is used to sample the Brillouin zone. For the geometry relaxations and energy calculations, van der Waals interactions are involved at the level of vdW-DF with the optB88 exchange functional 6,7 , and this prove to be very important to accurately evaluate the interactions between molecules/clusters and graphene/g- $C_{3} N_{4}$. The supercell box is fixed and all atoms are allowed to fully relax until the residual force per atom is less than $0.01 \mathrm{eV}^{-1}$. The charge population is calculated using Bader charge analysis ${ }^{8}$.

Catalytic performance. The experiments of OA removal $(2 \mathrm{mM}, 250 \mathrm{~mL})$ in peroxone process is performed in a columnar reactor. $10 \mathrm{uL} \mathrm{H}_{2} \mathrm{O}_{2}$ and $25 \mathrm{mg} \mathrm{Mn-CN}$ catalyst are added before reaction. $\mathrm{O}_{3}$ is continuously bubbled with a flow rate of $100 \mathrm{ml} \mathrm{min}^{-1}$ and a concentration of $30 \mathrm{mg} \mathrm{L}^{-1}$. Appropriate amount of solution is taken at certain time, and the concentration of residual OA is analyzed by ion chromatography. The concentration of $\mathrm{H}_{2} \mathrm{O}_{2}$ in solution is detected by the typical horseradish peroxidase method, before which residual $\mathrm{O}_{3}$ is firstly removed using indigo solution in testing liquid, 
and then the absorbance is detected using a ultraviolet spectrophotometer by adding N,N-two ethylpbenzyl-two amine sulphuric acid (DPD) and horseradish peroxidase (POD) one by one. $\cdot \mathrm{OH}$ and $\mathrm{HO}_{2} \cdot$ detection are performed by using an electron paramagnetic resonance (EPR, ELEXSYSs E50o, Bruker, 157 Germany) with 5, 5-dimethyl-1-pyrroline (DMPO) as the spin trapping agent.

Electrochemical measurement. The $\mathrm{H}_{2} \mathrm{O}_{2}$ oxidation current is detected in a three-electrode system. A platinum wire and a saturated calomel electrode (SCE) are used as the counter electrode and reference electrode, respectively. A glassy carbon electrode is used as the working electrode. It is conducted in $50 \mathrm{mM} \mathrm{Na}_{2} \mathrm{SO}_{4}$ solution with $1 \mathrm{mM} \mathrm{H}_{2} \mathrm{O}_{2}$ using the chronoamperometry method at a constant potential ( $0.8 \mathrm{~V}$ vs. SCE).

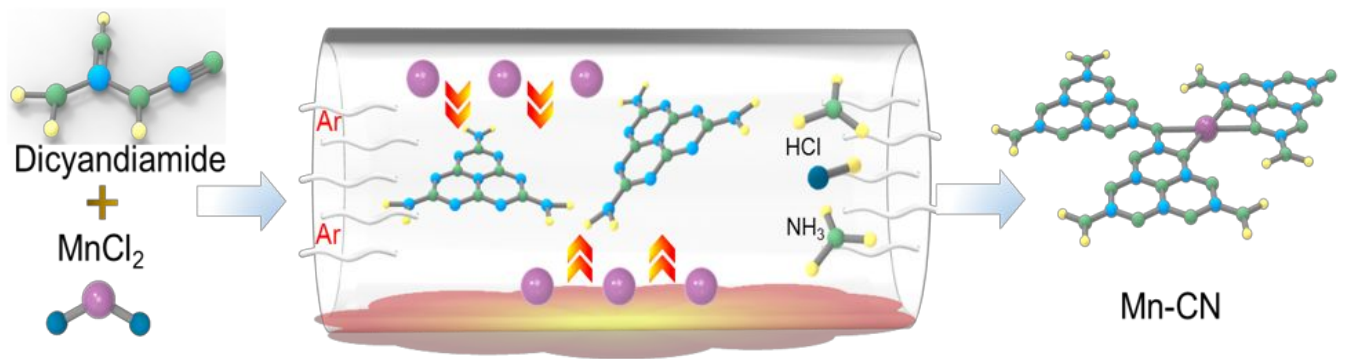

Figure S1. Schematic procedure for the synthesis of Mn-CN catalyst.

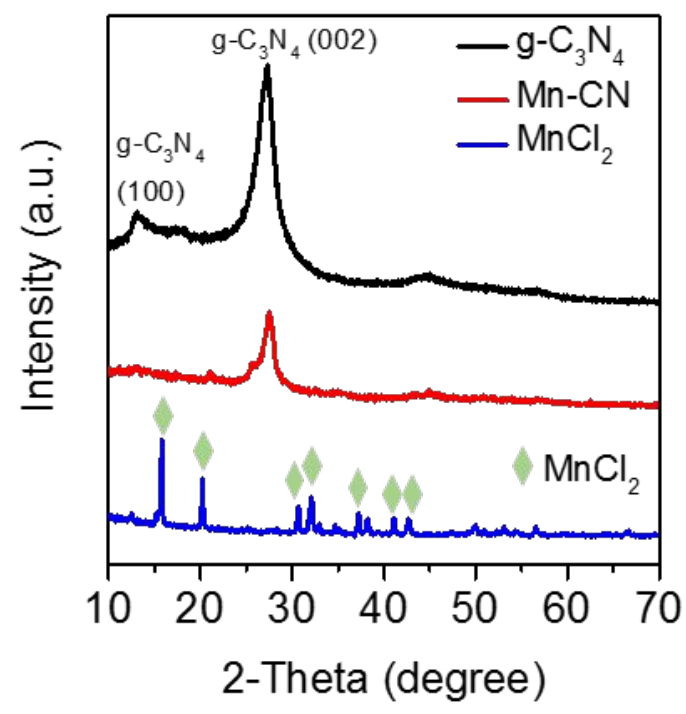

Figure S2. XRD patterns of g- $\mathrm{C}_{3} \mathrm{~N}_{4}, \mathrm{Mn}-\mathrm{CN}$ and $\mathrm{MnCl}_{2}$ catalysts. 


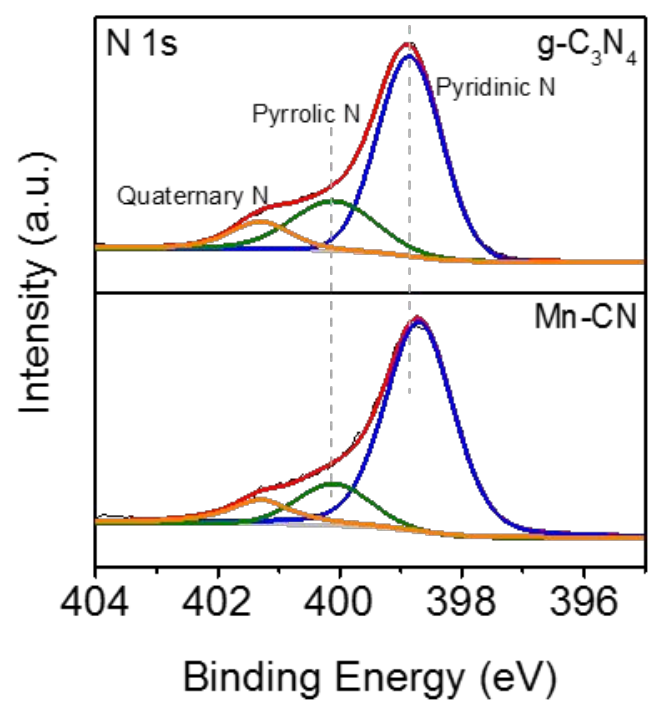

Figure $S_{3}$. The $\mathrm{N}$ is spectra of $\mathrm{g}-\mathrm{C}_{3} \mathrm{~N}_{4}$ and $\mathrm{Mn}-\mathrm{CN}$ catalyst.

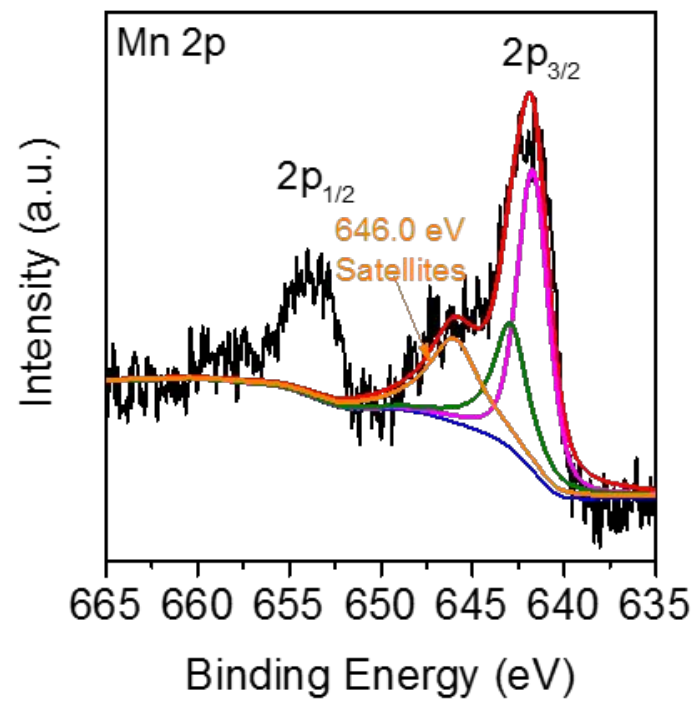

Figure 4 . The Mn 2p spectra of Mn-CN catalyst. 


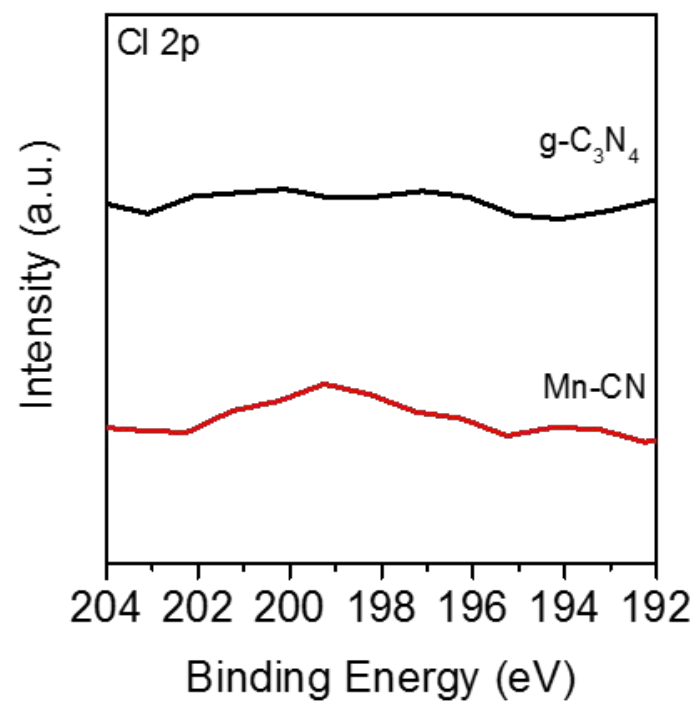

Figure $\mathrm{S}_{5}$. The $\mathrm{Cl} 2 \mathrm{p}$ spectra of $\mathrm{g}-\mathrm{C}_{3} \mathrm{~N}_{4}$ and $\mathrm{Mn}-\mathrm{CN}$ catalyst.
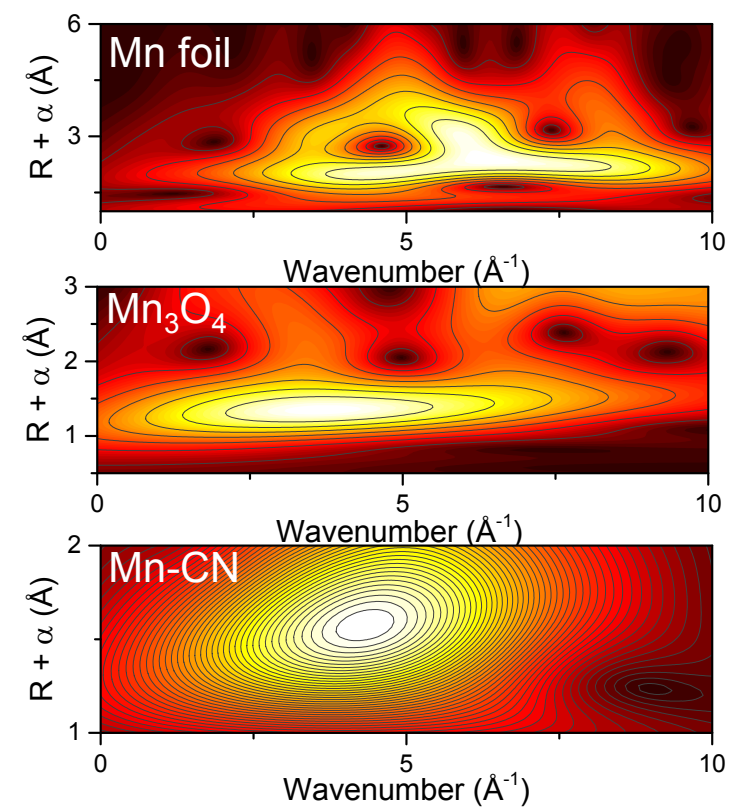

Figure S6. The Wavelet transform (WT) contour plots of $\mathrm{Mn}$ foil, $\mathrm{Mn}_{3} \mathrm{O}_{4}$ and $\mathrm{Mn}-\mathrm{CN}$ catalyst. 


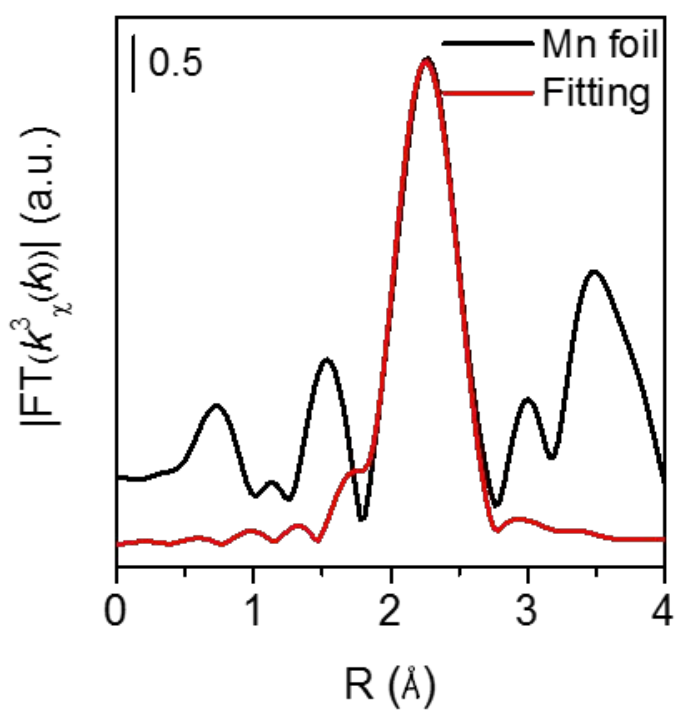

Figure $\mathrm{S}_{7}$. The EXAFS r space fitting curves of Mn foil catalyst.

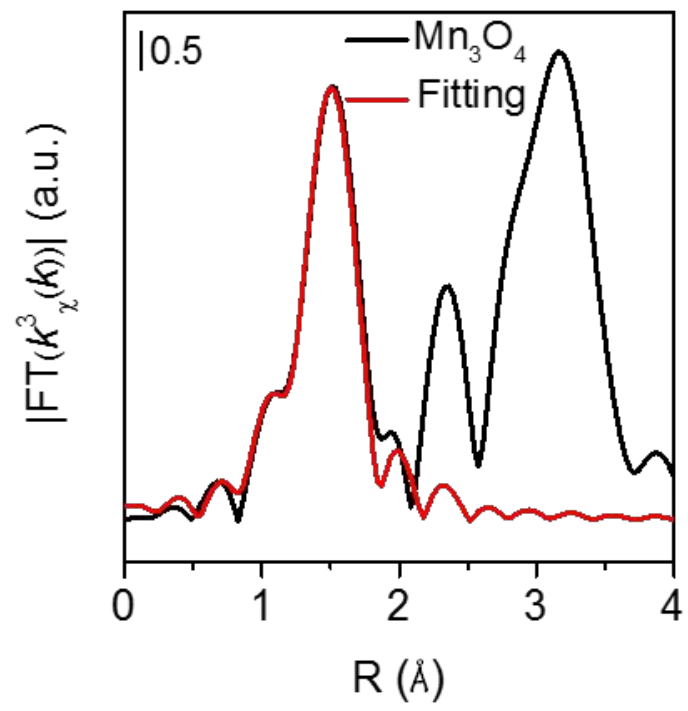

Figure S8. The EXAFS r space fitting curves of $\mathrm{Mn}_{3} \mathrm{O}_{4}$ catalyst. 


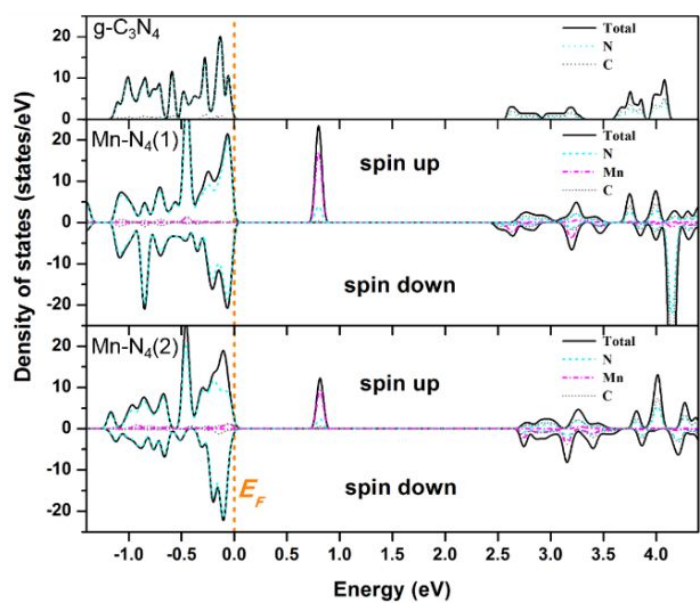

Figure S9. The calculated density of states (DOS) of pristine g- $\mathrm{C}_{3} \mathrm{~N}_{4}$ and Mn-doped g- $\mathrm{C}_{3} \mathrm{~N}_{4}$ with Mn$\mathrm{N}_{4}(1)$ and $M n-\mathrm{N}_{4}(2)$ configurations. The Fermi level (denoted by short dash line in yellow) is set to be the maximum of valence bands.

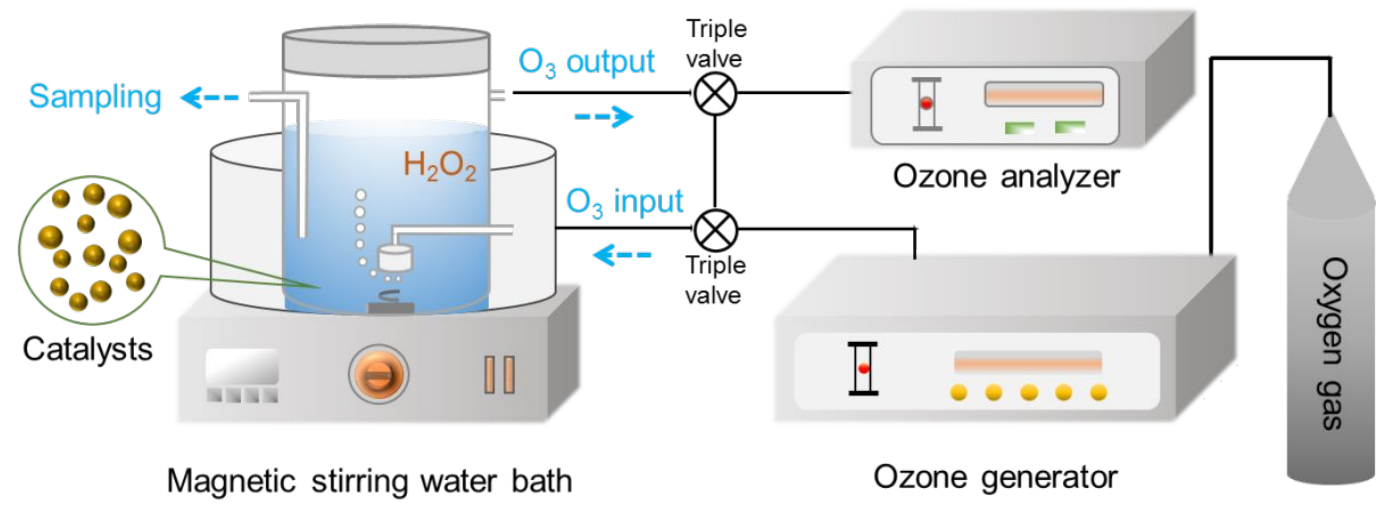

Figure S1o. Experimental setup of the peroxone process with Mn-CN catalyst.

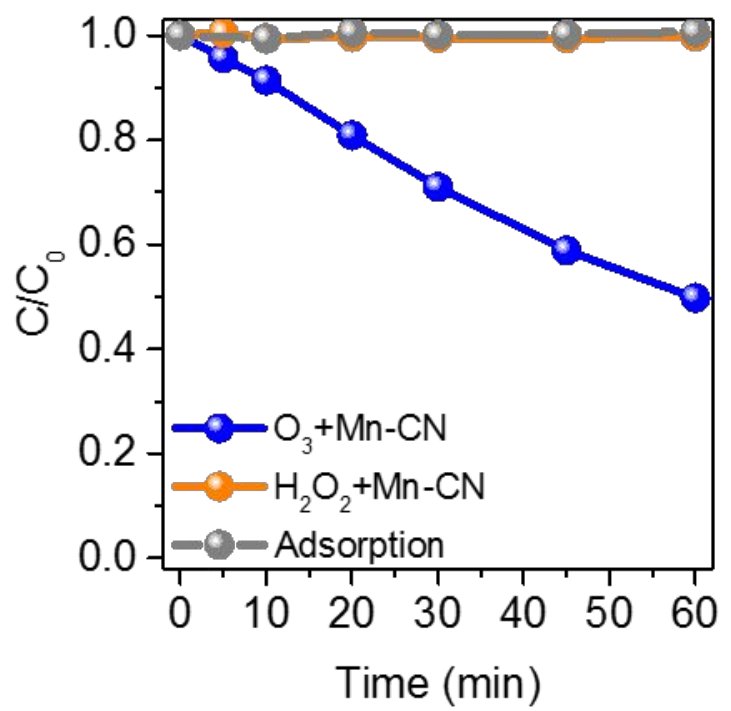

Figure S11. The degradation curves of $\mathrm{OA}$ in adsorption, ozonation or $\mathrm{H}_{2} \mathrm{O}_{2}$ process with $\mathrm{Mn}-\mathrm{CN}$ 
catalyst

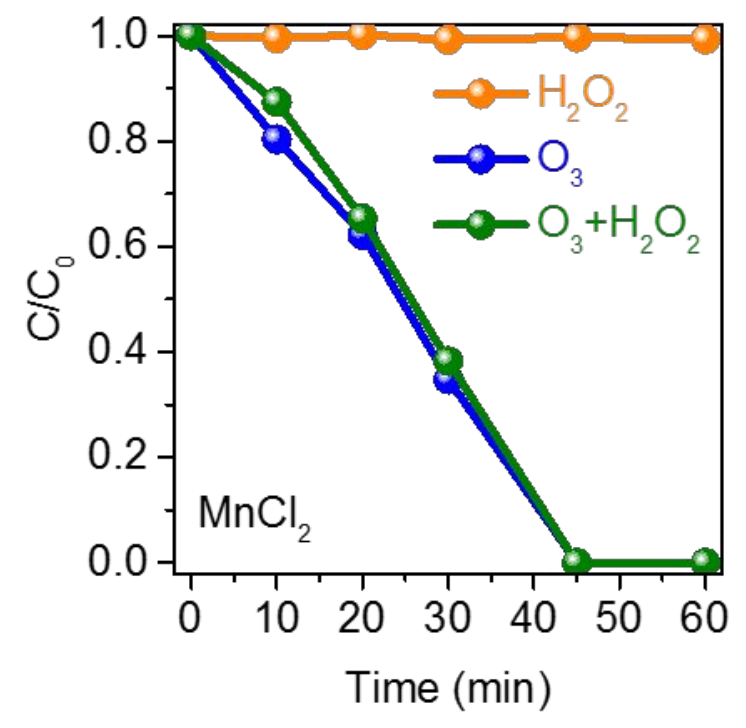

Figure $\mathrm{S}_{12}$. The degradation curves of $\mathrm{OA}$ in ozonation, $\mathrm{H}_{2} \mathrm{O}_{2}$ process or peroxone process with $\mathrm{MnCl}_{2}$ catalyst

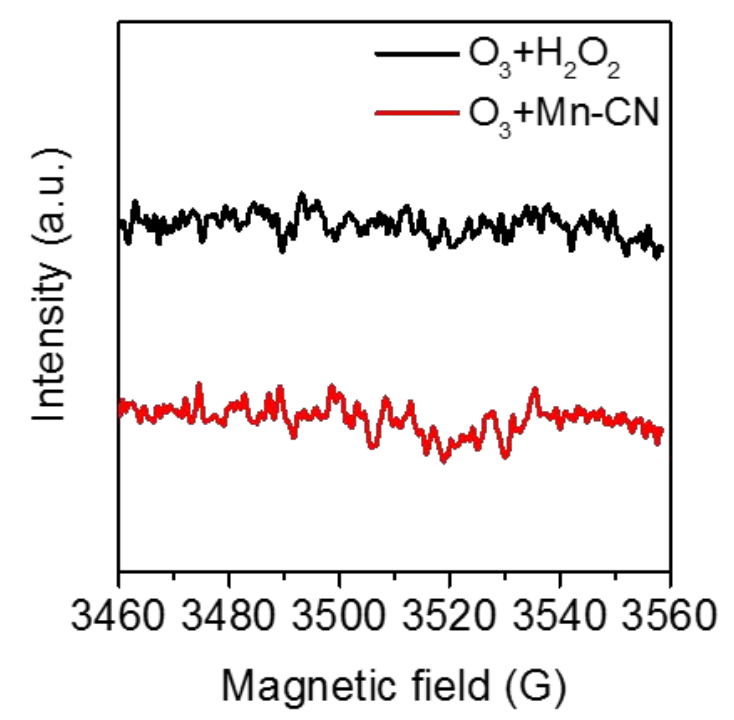

Figure S13. The EPR spectra of DMPO- $\mathrm{HO}_{2}{ }^{\cdot}$ adduct in peroxone process and catalytic ozonation process with Mn-CN catalyst. 
$\begin{array}{ll}\text { (a) } \mathrm{Mn}^{\mathrm{II}}-\mathrm{N}_{4} & \text { (b) } \mathrm{H}_{2} \mathrm{O}_{2} \text { adsorption }\end{array}$

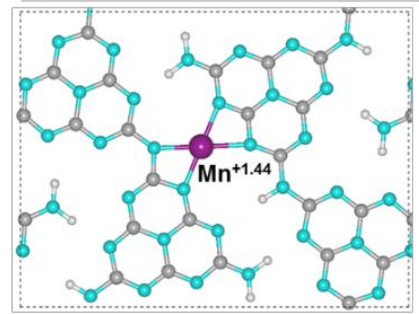

$E($ total $)=-390.429(\mathrm{eV})$

$N_{e}=298$

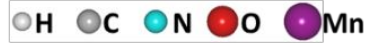

(c) $\mathrm{HOO}-\mathrm{Mn}^{\mathrm{II}}-\mathrm{N}_{4}$

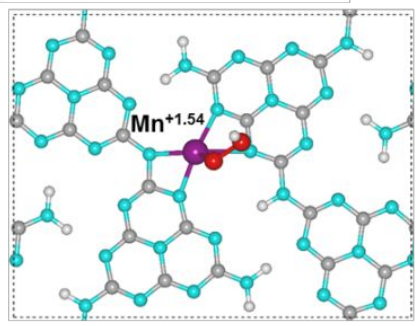

$\mathrm{E}($ total $)=-\mathbf{4 0 1 . 5 4 2}(\mathrm{eV})$

$N_{e}=312$

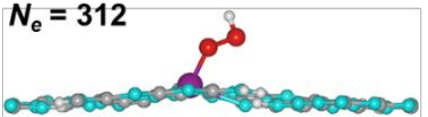

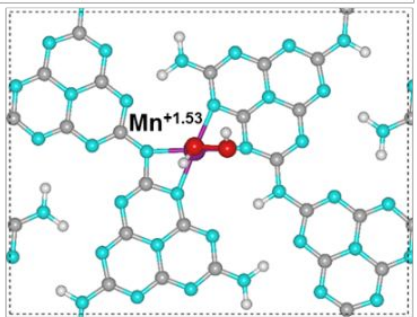

$E($ total $)=-403.317(\mathrm{eV})$

$N_{e}=312$

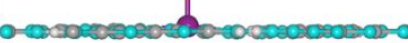

(d) $\mathrm{Mn}^{\mathrm{I}}-\mathrm{N}_{4}$

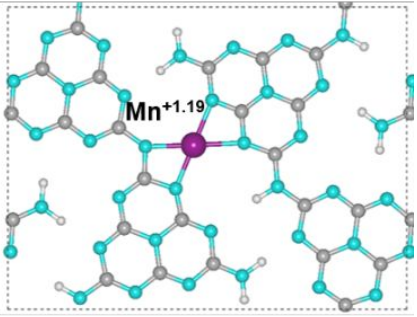

$E($ total $)=-391.650 \mathrm{eV}$

$N_{e}=299$

Figure S14. The schematic structures of (a) $\mathrm{Mn}^{2+}$-doped $\mathrm{C}_{3} \mathrm{~N}_{4}$ configuration, (b) the adsorption of $\mathrm{H}_{2} \mathrm{O}_{2}$, (c) -OOH on the $\mathrm{Mn}^{2+}$ site and (d) $\mathrm{Mn}^{1+}$-doped $\mathrm{C}_{3} \mathrm{~N}_{4}$ configuration. The corresponding total energies with dipole correction and the Bader charge of Mn cation are also given.

We simulated a $\mathrm{Mn}^{2+}$ cation doped $\mathrm{g}-\mathrm{C}_{3} \mathrm{~N}_{4}$ by setting the number of electrons of $\mathrm{Mn}-\mathrm{N}_{4}$ to be 298 , which should be $300(1 \times 13+11 \times 1+24 \times 4+36 \times 5=300)$ for the neutral case. The Bader charge analysis showed that the Mn cation was positively charged (+1.44), as shown in Figure S13. Then, we introduced a $\mathrm{H}_{2} \mathrm{O}_{2}$ molecule on the Mn site of this positively charged Mn- $\mathrm{N}_{4}$ system. Energy calculation showed that the adsorption of $\mathrm{H}_{2} \mathrm{O}_{2}$ on the $\mathrm{Mn}$ site was energetically stable with the adsorption energy of 1.04 $\mathrm{eV}$. The energy change from $\mathrm{H}_{2} \mathrm{O}_{2}-\mathrm{Mn}-\mathrm{N}_{4}$ to $\mathrm{HOO}-\mathrm{Mn}-\mathrm{N}_{4}$ was calculated to be $1.798 \mathrm{eV}$, confirming the existence of HOO-Mn- $\mathrm{N}_{4}$ bond.

(a) $\mathrm{H}_{2} \mathrm{O}_{2}$ molecule

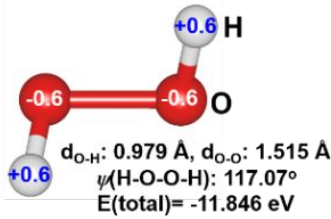

(c) $\mathrm{HO}_{2} \cdot$ radical

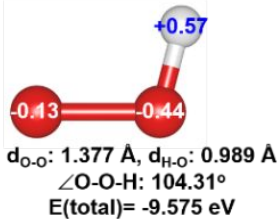

(b) $\mathrm{O}_{3}$ molecule

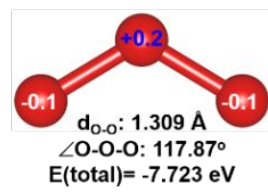

(d) $\mathrm{O}_{3} \cdot-$ radical

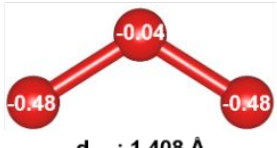

$\mathrm{d}_{0-0}: 1.408 \mathrm{~A}$ $\angle 0-0-0: 115.49^{\circ}$ $E($ total $)=-10.736 \mathrm{eV}$

Figure $\mathrm{S}_{15}$. The schematic structures of $\mathrm{H}_{2} \mathrm{O}_{2}$ molecule (a), $\mathrm{O}_{3}$ molecule (b), $\mathrm{HO}_{2}{ }^{\bullet}$ radical (c) and $\mathrm{O}_{3}$ • 
- radical (d). The calculated total energies with dipole correction, the Bader charge populations, and detailed structure information (bond length, bond angle, and dihedral angle) are also given.

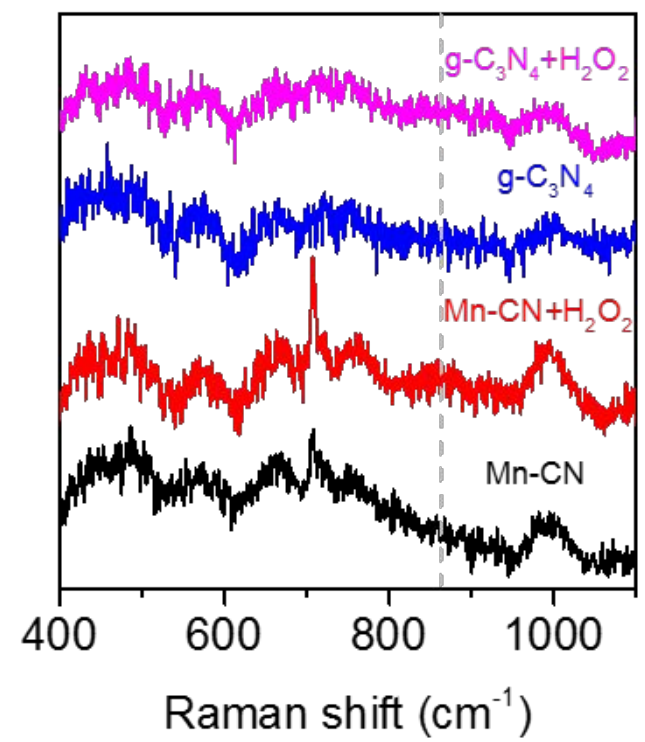

Figure S16. The Raman spectra of $\mathrm{Mn}-\mathrm{CN}$ and $\mathrm{g}-\mathrm{C}_{3} \mathrm{~N}_{4}$ with and without $\mathrm{H}_{2} \mathrm{O}_{2}$ solution. Comparing with Raman spectra of Mn-CN catalyst, g- $\mathrm{C}_{3} \mathrm{~N}_{4}$ material and suspension of $\mathrm{g}-\mathrm{C}_{3} \mathrm{~N}_{4}$ and $\mathrm{H}_{2} \mathrm{O}_{2}$, an obvious peak at $860 \mathrm{~cm}^{-1}$ is observed in the system with $\mathrm{Mn}-\mathrm{CN}$ and $\mathrm{H}_{2} \mathrm{O}_{2}$, which is deemed to be the adsorbed - $\mathrm{OOH}$ species. It should be mentioned that the -OOH species is normally detected by resonance Raman at excitation wavelength between 450 and $600 \mathrm{~nm}$, but the $\mathrm{Mn}-\mathrm{CN}$ catalyst exhibits very strong fluorescence peaks at these wavelengths. Therefore, the excitation wavelength of $785 \mathrm{~nm}$ is chosen in this work and the peak intensity is not very high.

Table S1. Parameters of EXAFS fits for Mn foil, $\mathrm{MnCl}_{2}, \mathrm{Mn}_{3} \mathrm{O}_{4}$ and $\mathrm{Mn}-\mathrm{CN}$ catalysts.

\begin{tabular}{cccccc}
\hline Samples & Path & $\mathrm{R}(\AA)$ & $\mathrm{N}$ & $\sigma^{2}(\AA)$ & $\Delta E^{0}(\mathrm{eV})$ \\
\hline $\mathrm{Mn}$ foil & $\mathrm{Mn}-\mathrm{Mn}$ & $2.66 \pm 0.04$ & 12 & 0.00001 & -6.81 \\
$\mathrm{MnCl}_{2}$ & $\mathrm{Mn}-\mathrm{Cl}$ & $2.476 \pm 0.021$ & 2 & 0.0047 & -2.03 \\
$\mathrm{Mn}_{3} \mathrm{O}_{4}$ & $\mathrm{Mn}-\mathrm{O}$ & $1.933 \pm 0.009$ & 6 & 0.0031 & 0.76 \\
$\mathrm{Mn}-\mathrm{CN}$ & $\mathrm{Mn}-\mathrm{N}$ & $2.217 \pm 0.028$ & $4.89 \pm 1.31$ & 0.0078 & 1.78 \\
\hline
\end{tabular}

\section{REFERENCES}

(1) Kresse, G.; Furthmüller, J. Phys. Rev. B 1996, 54, 11169.

(2) Kresse, G.; Joubert, D. Phys. Rev. B 1999, 59, 1758. 
(3) Perdew, J. P.; Burke, K.; Ernzerhof, M. Phys Rev Lett 1996, 77, 3865.

(4) Blöchl, P. E. Phys. Rev. B 1994, 50, 17953.

(5) Lotsch, B. V.; Döblinger, M.; Sehnert, J.; Seyfarth, L.; Senker, J.; Oeckler, O.; Schnick, W. Chem-Eur J 2007, 13, 4969.

(6) Klimeš, J.; Bowler, D. R.; Michaelides, A. J Phys-Condens Mat 2009, 22, 022201.

(7) Klimeš, J.; Bowler, D. R.; Michaelides, A. Phys. Rev. B 2011, 83, 195131.

(8) Henkelman, G.; Arnaldsson, A.; Jónsson, H. Comput. Mater. Sci. 2oo6, 36, 354. 